\title{
Changing glomerular filtration with progression from impaired glucose tolerance to Type II diabetes mellitus
}

\author{
R.G. Nelson ${ }^{1}$, M. Tan ${ }^{2}$, G.J. Beck ${ }^{2}$, P.H. Bennett ${ }^{1}$, W. C. Knowler ${ }^{1}$, W.E. Mitch ${ }^{3}$, K. Blouch ${ }^{4}$, B. D. Myers ${ }^{4}$ \\ ${ }^{1}$ Phoenix Epidemiology and Clinical Research Branch, National Institute of Diabetes and Digestive and Kidney Diseases, \\ Phoenix, Arizona, USA \\ ${ }^{2}$ Department of Biostatistics and Epidemiology, The Cleveland Clinic Foundation, Cleveland, Ohio, USA \\ ${ }^{3}$ Renal Division, Emory University School of Medicine, Atlanta, Georgia, USA \\ ${ }^{4}$ Division of Nephrology, Stanford University School of Medicine, Stanford, California, USA
}

\begin{abstract}
Summary Glomerular filtration rate (iothalamate clearance) was measured serially for 48 months in 26 Pima Indians with impaired glucose tolerance and 27 with normal glucose tolerance. At baseline, the mean glomerular filtration rate (SEM) was $133 \pm$ $8 \mathrm{ml} / \mathrm{min}$ in subjects with impaired glucose tolerance and $123 \pm 5 \mathrm{ml} / \mathrm{min}$ in those with normal glucose tolerance $(p=0.12)$. In the 12 subjects with impaired glucose tolerance who progressed to Type II (non-insulin-dependent) diabetes during follow-up, mean glomerular filtration rate increased by $30 \%(p=$ 0.011). Among the remaining 14 subjects with impaired glucose tolerance, 12 reverted to normoglycaemia.
\end{abstract}

The glomerular filtration rate both at baseline and after 48 months in this subgroup exceeded the values of subjects with normal glucose tolerance by $20 \%(p=$ $0.008)$ and $14 \%(p=0.013)$, respectively. A pronounced rise in the glomerular filtration rate occurs at the onset of Type II diabetes but a trend to hyperfiltration is also present in those with impaired glucose tolerance. [Diabetologia (1999) 42: 90-93]

Keywords Diabetic Renal Disease Study, glomerular filtration rate, impaired glucose tolerance, Type II diabetes, Pima Indians.
Glomerular hyperfiltration is a characteristic feature of patients with newly diagnosed Type I (insulin-dependent) diabetes [1], and the extent of this abnormality is associated with the prevailing level of hyperglycaemia [2]. A similar abnormality of glomerular function was reported in early Type II (non-insulindependent) diabetes $[3,4]$ but it cannot be attributed as convincingly to the initiation of diabetes. Not only is the onset of Type II diabetes more often insidious, but it is typically preceded by a variable period of impaired glucose tolerance (IGT) [5, 6], a designation adopted by the World Health Organization to de-

Received: 18 May 1998 and in revised form: 21 August 1998

Corresponding author: Dr. R. G. Nelson, National Institute of Diabetes and Digestive and Kidney Diseases, 1550 East Indian School Road, Phoenix, Arizona 85014-4972 USA

Abbreviations: GFR, Glomerular filtration rate; IgG, immunoglobulin G; IGT, impaired glucose tolerance; MAP, mean arterial pressure; NGT, normal glucose tolerance; RPF, renal plasma flow. scribe those who have abnormal glucose tolerance that is not diagnostic of diabetes, and who are at high risk of progression to diabetes [7]. To determine the rate of glomerular filtration (GFR) associated with IGT and the changes that occur with progression to Type II diabetes, we measured the urinary clearance of iothalamate serially over four years in 53 Pima Indians, 26 with IGT and 27 with normal glucose tolerance (NGT).

\section{Subjects and methods}

The protocol was approved by the review boards of the National Institute of Diabetes and Digestive and Kidney Diseases, Stanford University, and the Cleveland Clinic Foundation, and by the Tribal Council of the Gila River Indian Community. Each subject gave informed consent.

Nondiabetic Pima or the closely related Tohono O'odham Indians residing in the Gila River Indian Community in Arizona participated in this study. Oral glucose tolerance tests were done in volunteers with normal serum creatinine concentrations $[<115 \mu \mathrm{mol} / \mathrm{l}(1.3 \mathrm{mg} / \mathrm{dl})$ in $\mathrm{men},<97 \mu \mathrm{mol} / \mathrm{l}(1.1 \mathrm{mg} / \mathrm{dl})$ 
Table 1. Clinical characteristics and glomerular function (mean \pm SE) at baseline and after 48 months in subjects with IGT according to whether or not they progressed to Type II diabetes

\begin{tabular}{|c|c|c|c|c|}
\hline & \multicolumn{2}{|c|}{ Non-progressors $(n=12)$} & \multicolumn{2}{|c|}{ Progressors $(n=12)$} \\
\hline & Baseline & 48 months & Baseline & 48 months \\
\hline Men, women & 3,9 & & 5,7 & \\
\hline Weight (kg) & $100 \pm 6$ & $106 \pm 7^{\mathrm{a}}$ & $112 \pm 9$ & $114 \pm 9$ \\
\hline Body mass index $\left(\mathrm{kg} / \mathrm{m}^{2}\right)$ & $38.6 \pm 2.4$ & $40.8 \pm 2.8^{\mathrm{a}}$ & $40.9 \pm 3.2$ & $41.5 \pm 3.3$ \\
\hline MAP $(\mathrm{mm} \mathrm{Hg})$ & $91 \pm 2$ & $87 \pm 3$ & $95 \pm 3$ & $94 \pm 3$ \\
\hline Fasting blood glucose (mmol/l) & $5.9 \pm 0.3$ & $4.9 \pm 0.2^{\mathrm{a}}$ & $6.0 \pm 0.4$ & $8.2 \pm 1.4^{\mathrm{c}}$ \\
\hline Serum creatinine $(\mu \mathrm{mol} / \mathrm{l})$ & $61 \pm 4$ & $69 \pm 2$ & $73 \pm 6^{\mathrm{c}}$ & $65 \pm 3$ \\
\hline Albumin-to-creatinine ratio $(\mathrm{mg} / \mathrm{g})^{\mathrm{b}}$ & $16.9(3.2-62.9)$ & $10.1(3.1-41.5)$ & $14.0(5.6-55.3)$ & $8.3(2.8-20.6)$ \\
\hline IgG-to-creatinine ratio $(\mathrm{mg} / \mathrm{g})^{\mathrm{b}}$ & $5.6(0.7-14.8)$ & $5.0(0.9-12.1)$ & $7.6(2.3-21.7)$ & $5.6(1.8-15.9)$ \\
\hline GFR (ml/min) & $147 \pm 12$ & $158 \pm 8$ & $116 \pm 9^{c}$ & $151 \pm 13^{\mathrm{a}}$ \\
\hline $\mathrm{RPF}(\mathrm{ml} / \mathrm{min})$ & $826 \pm 72$ & $771 \pm 50$ & $710 \pm 54^{\mathrm{c}}$ & $784 \pm 75$ \\
\hline Filtration fraction & $0.18 \pm 0.01$ & $0.21 \pm 0.01$ & $0.16 \pm 0.01$ & $0.19 \pm 0.01$ \\
\hline
\end{tabular}

${ }^{a} p<0.05$ vs baseline.

${ }^{\mathrm{b}}$ Median (range).

${ }^{\mathrm{c}} p<0.05$ vs non-progressors.

in women] and no evidence of nondiabetic renal disease. A fasting plasma glucose less than $7.8 \mathrm{mmol} / \mathrm{l}(140 \mathrm{mg} / \mathrm{dl})$ and a 2-h post-load plasma glucose less than $7.8 \mathrm{mmol} / \mathrm{l}$ identified 27 subjects with NGT. Corresponding ranges of less than $7.8 \mathrm{mmol} / \mathrm{l}$ for fasting glucose and between 7.8 and $11.1 \mathrm{mmol} / \mathrm{l}$ $(200 \mathrm{mg} / \mathrm{dl})$ for $2 \mathrm{~h}$ glucose on two occasions identified $26 \mathrm{sub}$ jects with IGT [7].

Glomerular function was measured in the subjects with NGT at baseline and after 48 months. Of the 25 subjects from the NGT group who had a final evaluation at 48 months, nine were excluded from analysis for the 48 months comparison as seven developed IGT and two developed diabetes. Oral glucose tolerance tests and measures of glomerular function were done annually over a 4 year period in those with IGT. Diabetes was diagnosed when fasting or $2 \mathrm{~h}$ post-load plasma glucose concentrations first equalled or exceeded 7.8 or $11.1 \mathrm{mmol} / \mathrm{l}$, respectively [7].

Each subject underwent renal clearance studies under conditions of water diuresis, as described previously [8]. GFR and renal plasma flow (RPF) were calculated as the average urinary clearances of iothalamate and para-aminohippuric acid, respectively. Concentrations of albumin and immunoglobulin $\mathrm{G}(\mathrm{IgG})$ in urine were measured by nephelometry, and excretion ratios relative to creatinine were computed. Mean arterial blood pressure (MAP) was measured at the beginning of the first clearance period.

Statistical analysis. Results are expressed as the means \pm SEM, except for urinary protein excretion which was expressed as the median and range. Clinical features and measures of glomerular function were compared between groups by analysis of covariance, with adjustment for age and sex. Differences in median urinary albumin-to-creatinine and IgG-to-creatinine ratios, and in glomerular membrane variables were analyzed by non-parametric one-way analysis of variance. Changes in the variables monitored during follow-up were assessed by paired $t$-tests or by Wilcoxon signed rank tests, depending on their distribution.

\section{Results}

At baseline, the subjects with IGT $(n=26)$ were heavier $(105 \pm 5$ vs $86 \pm 4 \mathrm{~kg} ; p=0.006)$ and more obese, as judged by body mass index [39.2 \pm 1.9 vs $\left.31.7 \pm 1.4 \mathrm{~kg} / \mathrm{m}^{2} ; p=0.002\right)$, than those with NGT $(n=27)$. Mean age, MAP, fasting glucose concentration, and creatinine concentration were similar in both groups. The median urinary albumin-to-creatinine ratio was greater in subjects with IGT than in those with NGT (14 vs $6 \mathrm{mg} / \mathrm{g} ; p=0.057)$. Mean IgG-to-creatinine ratios were similar in both groups. Absolute GFR and RPF \pm SEM were slightly higher in subjects with IGT than in those with NGT $(133 \pm 8$ vs $123 \pm 5 \mathrm{ml} / \mathrm{min}$ for GFR, $784 \pm 45$ vs $738 \pm 30 \mathrm{ml} / \mathrm{min}$ for $\mathrm{RPF}$ ), and these differences were no longer apparent when divided by body surface area $\left[110 \pm 6\right.$ vs $110 \pm 4 \mathrm{ml} \cdot \mathrm{min}^{-1} \cdot 1.73 \mathrm{~m}^{-2}$ for GFR, $652 \pm 35$ vs $668 \pm 29 \mathrm{ml} \cdot \mathrm{min}^{-1} \cdot 1.73 \mathrm{~m}^{-2}$ for RPF].

Among the 26 subjects with IGT at baseline who completed 48 months of follow-up, 12 developed Type II diabetes and were designated "progressors". Twelve of the subjects returned to a state of NGT and were designated "non-progressors". Two subjects did not have oral glucose tolerance tests after 48 months and could not be classified; they were excluded from the longitudinal analyses. Differences between the progressors and non-progressors are shown in Table 1 . The initial GFR was lower in those with IGT who developed Type II diabetes than in non-progressors $(116 \pm 9$ vs $147 \pm 10 \mathrm{ml} / \mathrm{min} ; p=$ $0.003)$, as was the RPF ( $710 \pm 54$ vs $826 \pm 72 \mathrm{ml} / \mathrm{min}$; $p=0.019)$. The baseline GFR in the IGT non-progressors was significantly higher than in subjects with NGT; $147 \pm 12$ vs $123 \pm 5 \mathrm{ml} / \mathrm{min}$, respectively $p=0.008$ ).

Of 30 GFR determinations made in the 12 progressors after the development of diabetes, 27 were above the baseline value, and 11 of the 12 subjects had higher values at the first examination after the onset of diabetes than at baseline (Fig.1). At 48 months, the GFR was above the baseline value in all but one of the 12 progressors. By contrast, GFR 

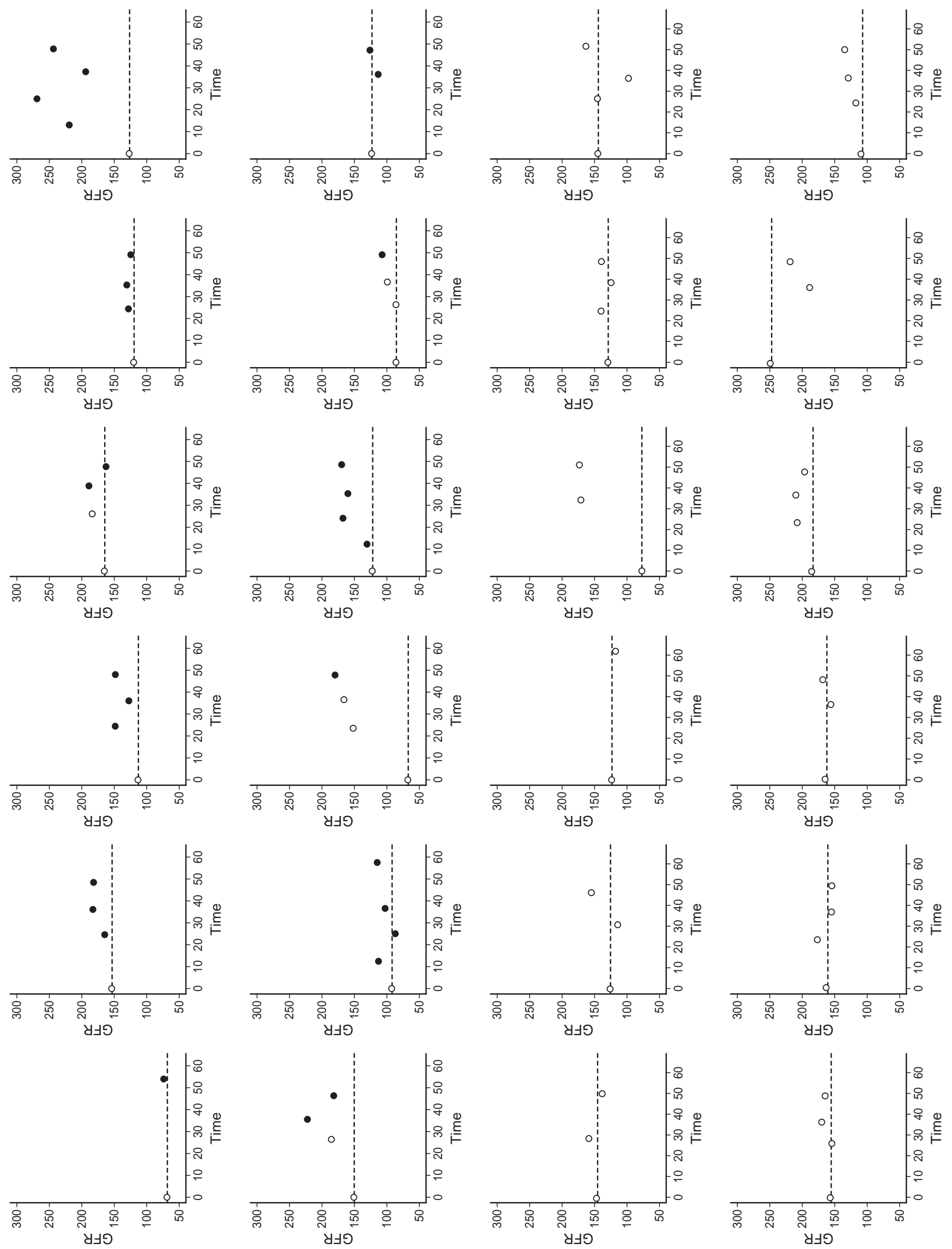

Fig. 1. Sequential GFR ( $\mathrm{ml} / \mathrm{min})$ in subjects with IGT. Subjects who progressed to diabetes are shown in the upper two rows and the represent GFR measurements taken after the onset of diabetes. Time is months from baseline examination 
fluctuated rather evenly on either side of the baseline in the 12 non-progressors (Fig. 1). The GFR remained higher in the non-progressors after 48 months than in the 16 subjects with persistent NGT $(158 \pm 8$ vs $138 \pm 7 \mathrm{ml} / \mathrm{min} ; p=0.013)$, although the differences were smaller when divided by the body surface area $\left[133 \pm 7\right.$ vs $123 \pm 6 \mathrm{ml} \cdot \mathrm{min}^{-1} \cdot 1.73 \mathrm{~m}^{-2}$; $p=0.18$ ). While the GFR was higher at 48 months than at baseline in 8 of the 12 non-progressors, with one exception this increase was modest. On the other hand, the GFR increased, on average by $30 \%$ in the progressors. The rise in GFR in progressors was associated with an increase in RPF, whereas in the nonprogressors the RPF was lower. Neither MAP nor urinary albumin-to-creatinine or IgG-to-creatinine ratios changed substantially over 48 months in the progressors or non-progressors.

\section{Discussion}

Hyperfiltration is a characteristic feature of newly-diagnosed Type II diabetes [3, 4], and this study shows that GFR increases, on average, by $30 \%$ contemporaneously with the transition from IGT to Type II diabetes in Pima Indians. The precise mechanism by which diabetes mediates glomerular hyperfiltration, however, is not known. Micropuncture studies in the rat point to the development of glomerular capillary hypertension with an ensuing increase in filtration pressure. Our study suggests a similar phenomenon in humans, since the GFR increased by $30 \%$ when subjects progressed from IGT to diabetes, whereas the corresponding increase in RPF averaged only $10 \%$ (Table 1). A simultaneous change in another determinant of GFR besides RPF, therefore, must be invoked to explain the observed enhancement of GFR, and an increase in glomerular capillary hydraulic pressure is a likely candidate.

Among the subjects with IGT who did not progress to diabetes, the absolute GFR at baseline was $20 \%$ higher than in those with NGT, $147 \pm 12$ vs $123 \pm$ $5 \mathrm{ml} / \mathrm{min}$, and a difference of $14 \%$ persisted after 48 months, $158 \pm 8$ vs $138 \pm 7 \mathrm{ml} / \mathrm{min}$, despite a fall in fasting blood glucose in these subjects. These differences in GFR are minimized when the standard practice of dividing the GFR by the body surface area is followed, but this "correction" may be inappropriate, particularly when differences in body surface area are primarily due to obesity. We cannot explain why the baseline GFR in the IGT group that progressed to diabetes was lower than that in the non-progressors but none of the subjects had any evidence of preexisting kidney disease on review of clinical records.

Glomerular hyperfiltration has been proposed as a precursor of chronic diabetic glomerular disease [9].
The role of an increased GFR, however, is controversial and while it is associated with development of progressive renal disease in Type I diabetes [10], it might not have a causal role. Indeed, in Pima Indians with Type II diabetes, increased GFR did not predict progression of renal disease over a 4-year period [8]. Nevertheless, a pronounced rise in the GFR does occur at the onset of Type II diabetes and a trend to hyperfiltration is also present in those with impaired glucose tolerance. The long-term effect of these haemodynamic changes on the development and course of renal disease in Type II diabetes remains to be determined.

Acknowledgements. This work was supported in part by contracts N01-DK-6-2285 and N01-DK-7-2291 from the National Institute of Diabetes and Digestive and Kidney Diseases. The authors are indebted to the members of the Gila River Indian Community for participating in this investigation; to R. Lovelace for recruiting the subjects; to L. Jones for carrying out the renal clearance studies; to L. Phillips and J. Loebel in Phoenix for doing the assays; and to R. Berg and K. Fatica of the Department of Biostatistics and Epidemiology, The Cleveland Clinic Foundation, for analyzing and processing the data.

\section{References}

1. Mogensen CE (1971) Kidney function and glomerular permeability to macromolecules in early juvenile diabetes. Scand J Clin Lab Invest 28: 79-90

2. Christiansen JS, Gammelgaard J, Tronier B, Svendsen PA, Parving H-H (1982) Kidney function and size in diabetics before and during initial insulin treatment. Kidney Int 21: 683-688

3. Myers BD, Nelson RG, Williams GW et al. (1991) Glomerular function in Pima Indians with noninsulin-dependent diabetes mellitus of recent onset. J Clin Invest 88: 524-530

4. Vora JP, Dolben J, Dean JD et al. (1992) Renal hemodynamics in newly presenting non-insulin dependent diabetes mellitus. Kidney Int 41: 829-835

5. Jarrett RJ, Keen H, Fuller JH, McCartney M (1979) Worsening to diabetes in men with impaired glucose tolerance ("borderline diabetes"). Diabetologia 16: 25-30

6. Saad MF, Knowler WC, Pettitt DJ, Nelson RG, Mott DM, Bennett PH (1988) The natural history of impaired glucose tolerance in the Pima Indians. $\mathrm{N}$ Engl J Med 319: $1500-1506$

7. World Health Organization Study Group on Diabetes Mellitus (1985) Technical report series No. 727, WHO, Geneva

8. Nelson RG, Bennett PH, Beck GJ et al. (1996) Development and progression of renal disease in Pima Indians with non-insulin-dependent diabetes mellitus. N Engl J Med 335: 1636-1642

9. Hostetter TH, Rennke HG, Brenner BM (1982) The case for intrarenal hypertension in the initiation and progression of diabetic and other glomerulopathies. Am J Med 72: $375-380$

10. Mogensen CE, Christensen CK (1984) Prediction of diabetic nephropathy in insulin-dependent patients. N Engl J Med 311: 89-93 